\title{
Estruturação de Processos na Área de Eventos: um estudo de caso em uma empresa em Santa Maria - RS
}

\author{
Structuring of Processes in the Area of Events: a case study in a company in \\ Santa Maria - RS

\section{Estructuración del Procesos en el Área de Eventos: un estudio de caso en una empresa en Santa Maria - RS}

\author{
Aline Armanini Stefanan ${ }^{1}$ \\ Lisiane Pellini Faller ${ }^{2}$ \\ Vânia Medianeira Flores Costa ${ }^{3}$
}

\begin{abstract}
Resumo
Este trabalho teve como objetivo estruturar os processos organizacionais existentes em uma empresa que atua na área de eventos em Santa Maria, RS, Brasil, com a finalidade de agregar valor à empresa e a seus clientes por meio da uniformização dos mesmos. Em relação ao método, o trabalho caracteriza-se como um estudo de caso realizado por meio de pesquisa bibliográfica de cunho descritivo e caráter qualitativo. A coleta dos dados foi feita por meio de observações in loco das atividades e dos processos realizados na empresa, pesquisa documental e entrevistas informais com os colaboradores, resultando na elaboração de fluxogramas e procedimentos operacionais padrão das principais atividades da empresa. Conclui-se, portanto, que o objetivo geral proposto foi atingido com tais melhorias para a empresa, ao proporcionar o estabelecimento de padrões de rotinas diárias e elaborar estratégias para guiar a organização no alcance de seus objetivos. Sugere-se para estudos futuros, maior exploração da área de eventos na forma de prestação de serviços e para a empresa em questão, a continuação do estudo dos processos organizacionais e a elaboração de um planejamento estratégico.
\end{abstract}

Palavras-chave: Serviços; Eventos; Estrutura Organizacional; Processos.

\footnotetext{
${ }^{1}$ Administradora pela Universidade Federal de Santa Maria, acadêmica de Estatística na Universidade Federal de Santa Maria - RS. Brasil.aline_1934@yahoo.com.br

${ }^{2}$ Mestre em Administração pela Universidade Federal de Santa Maria. Docente no curso de Administração da Faculdade Metodista de Santa Maria - RS. Brasil. lisi.faller@yahoo.com.br

${ }^{3}$ Doutora em Administração pela Universidade Federal da Bahia. Docente do Departamento de Ciências Administrativas da Universidade Federal de santa Maria (UFSM). Brasil. vania.costa@ufsm.br
} 


\begin{abstract}
The objective of this study is to structure the organizational processes at a company in the area of events in Santa Maria, RS, Brazil, in order to add value to the company and its customers by standardizing the processes. Regarding the method, the work is characterized as a qualitative descriptive case study through bibliographic research. Data collection was performed by local observations of activities and processes performed in the company, documentary research and informal interviews with employees, resulting in the flowcharts and standard operating procedures of the main activities of the company. It is concluded, therefore, that objective was achieved with such improvements to the company by providing the establishment of standards of daily routines and develop strategies to guide the organization in achieving its goals. It is suggested for future studies, further exploration of the area of events in the form of service companies and for the company in question, continued study of organizational processes and the development of a strategic plan.
\end{abstract}

Keywords: Services, Events, Organizational Structure, Processes.

\title{
Resumen
}

Este estudio tuvo como objetivo estructurar los procesos organizativos existentes en una empresa que opera en los eventos en Santa Maria, RS, Brasil. El trabajo se caracteriza por ser un estudio de caso llevado a cabo por medio de la literatura a partir de un estudio descriptivo y cualitativo. La recolección de datos se realiza por medio de observaciones in situ de las actividades y procesos realizados en la empresa, la investigación documental y entrevistas informales con los empleados, lo que resulta en la elaboración de procedimientos normalizados de trabajo y diagramas de flujo de las principales actividades de la empresa. De ello se desprende que el objetivo se logró con estas mejoras a la compañía, proporcionando el establecimiento de las pautas de la rutina diaria y desarrollar estrategias para guiar a la organización en el logro de sus objetivos. Se sugiere para futuros estudios, la exploración adicional de los eventos de la zona en forma de servicios y la empresa en cuestión, un mayor estudio de los procesos de organización y el desarrollo de un plan estratégico.

Palabras clave: servicios, eventos, estructura organizacional, procesos.

\section{Introdução}

A relevância do setor de serviço em nossa sociedade pode ser demonstrada pela análise das tendências e transformações que a economia mundial está vivenciando. Corrêa e Gianesi (1995) apontam fatores como a busca de qualidade de vida e mais tempo de lazer, o aumento da sofisticação dos consumidores, a urbanização, a evolução tecnológica, o aumento de 
crianças e idosos, assim como a participação da mulher no trabalho remunerado e as pressões sobre o tempo pessoal para explicar o aumento da demanda por atividades de serviço.

Matias (2007) destaca que a organização de eventos é um tipo de prestação de serviços que vem crescendo muito em todo o mundo e se tornando uma importante fonte econômica, além de gerar inúmeros benefícios sociais.

Conforme Veloso (2001, p.3), “os eventos e as cerimônias constituem-se em meios de estabelecer a comunicação aproximativa entre pessoas e públicos de organizações governamentais e privadas". Segundo Matias (2001, p. 61), evento é "ação do profissional mediante pesquisa, planejamento, organização, coordenação, controle e implantação de um projeto, visando atingir seu público-alvo com medidas concretas e resultados projetados".

A organização de um evento é dividida em pré-evento, o acontecimento do evento e o pósevento, conforme Martin (2007), sendo que quanto melhor for preparada a fase de pré-evento, ou seja, o planejamento do mesmo, maior a chance de sucesso. $\mathrm{O}$ autor define pré-evento como sendo:

(...) a fase essencial do evento, onde haverá a definição do projeto e o planejamento de todas as atividades, bem como o detalhamento de receitas e despesas esperadas, com a decisão de que tipo de fornecedores e profissionais deverá ser contratado. Também são equacionados os controles administrativos e financeiros (MARTIN, 2007, p.72).

De forma a complementar, Matias (2001, p.98) afirma que a fase de planejamento "é a peça fundamental num processo de organização de um evento. É a fase decisiva do evento, na qual estão inseridos a coordenação executiva e os controles financeiro, técnico-administrativo e social do evento". De acordo com Cesca (2008), o planejamento de um evento envolve objetivos, públicos, estratégias, recursos, implantação, fatores condicionantes, acompanhamento e controle, avaliação e orçamento previsto, conforme apresentado no Quadro 1 - Etapas do Planejamento de Eventos. 


\section{Quadro 1: Etapas do Planejamento de Eventos}

\begin{tabular}{|l|l|}
\hline $\begin{array}{l}\text { Etapas do planejamento } \\
\text { de eventos }\end{array}$ & Descrição \\
\hline Objetivos & O que se pretende com o evento, de forma ampla e específica. \\
\hline Públicos & A quem se destina o evento. \\
\hline Estratégias & O que serve de atração para o público de interesse do evento. \\
\hline Recursos & Os fatores humanos, materiais e físicos que serão utilizados no evento. \\
\hline Implantação & A descrição dos procedimentos da aprovação ao término do projeto. \\
\hline Fatores condicionantes & $\begin{array}{l}\text { Os fatos, decisões e acontecimentos dos quais o projeto depende para sua } \\
\text { realização. }\end{array}$ \\
\hline $\begin{array}{l}\text { Acompanhamento e } \\
\text { controle }\end{array}$ & $\begin{array}{l}\text { A determinação de quem fará a coordenação de todo o processo e como } \\
\text { ela será feita. }\end{array}$ \\
\hline Avaliação & $\begin{array}{l}\text { O relatório de prestação de contas ao término do evento entregue a quem } \\
\text { solicitou a organização do evento. }\end{array}$ \\
\hline Orçamento previsto & $\begin{array}{l}\text { A previsão dos custos detalhadamente, pois a partir dele virão os recursos } \\
\text { financeiros necessários para o pagamento dos recursos humanos, } \\
\text { materiais e físicos. }\end{array}$ \\
\hline
\end{tabular}
Fonte: Adaptado de Cesca (2008, p. 49-50).

Cesca (2008) ressalta que todos os eventos passam pelas etapas mencionadas no Quadro 1, mas a complexidade de cada um depende do tipo de evento a ser organizado e do seu tempo de duração.

A partir do exposto, compreende-se que a organização de eventos exige muito conhecimento e responsabilidade de quem atua na área, já que os eventos acontecem em tempo real e qualquer falha compromete além do evento em questão, a imagem da empresa. Por isso, é importante que as empresas que trabalham com a organização de eventos tenham seus processos bem estruturados, de forma a minimizar a possibilidade de falhas na execução de seus serviços.

Uma vantagem competitiva de longo prazo em termos de serviços depende da qualidade do projeto do serviço e de seu processo de fornecimento e, para conseguir tal vantagem, a empresa deve organizar os seus recursos e firmar um padrão de decisões coerente (CORRÊA; GIANESI, 1995). 
Valeriano (2001, apud SENTANIN, 2003, p. 2) afirma que "todas as atividades técnicas, gerenciais e administrativas podem ser estudadas sob a forma de processo. Entende-se por processo um conjunto inter-relacionado de atividades que transformam entradas em saídas".

Quinn (1992 apud GONÇALVES, 2000) ressalta que a importância do emprego do conceito de processo nas empresas aumenta à medida que se tem que trabalhar com um conteúdo cada vez mais intelectual e oferecer produtos cada vez mais ricos em valores intangíveis, fatores estes característicos das empresas prestadoras de serviços, o que salienta a importância de se trabalhar o conceito de processo nestas organizações.

No trabalho das organizadoras de eventos, o cliente deve interagir no papel de participante do processo. Combinar a capacidade de atender aos serviços com a demanda é uma tarefa complicada para estas empresas, pois a procura dos clientes ocorre de acordo com sua vontade e, em grande parte, são demandas únicas. Em processos de serviço, o cliente participa da produção do serviço em algum ponto e assim os problemas são diretamente percebidos pelo cliente. Santos (2000) sugere que o ponto de partida para melhoria da qualidade em serviços está nas atividades que são percebidas pelo cliente, não se esquecendo da adequada gestão dos processos que produzem estes serviços.

Por meio da estruturação dos processos da empresa, pretende-se, portanto, aprimorar as atividades operacionais realizadas na empresa, melhorando o desempenho e minimizando incertezas e retrabalho na organização, conseguindo, assim, desenvolver uma vantagem competitiva de longo prazo.

Dentro desta perspectiva, espera-se responder o seguinte problema de pesquisa: Como os processos devem ser estruturados na empresa de forma a agregar valor à mesma e a seus clientes?

Visando responder tal problema, foi elaborado o seguinte objetivo geral: estruturar os processos organizacionais existentes na empresa com a finalidade de agregar valor à mesma e a seus clientes por meio da uniformização dos mesmos.

Os objetivos específicos do estudo foram mapear os principais processos organizacionais da organização; identificar as responsabilidades dos atuantes dentro dos processos; levantar 
possíveis falhas no andamento dos processos; e propor sugestões de melhoria para o melhor desenvolvimento das atividades da empresa.

Com o presente estudo, pretendeu-se realizar o mapeamento dos processos operacionais da empresa, com posterior revisão e análise para implementação dos ajustes necessários à otimização das atividades realizadas por uma empresa prestadora de serviços na área de eventos na cidade de Santa Maria / RS.

A gestão dos processos é essencial nas organizações, sobretudo nas prestadoras de serviços, uma vez que em tais empresas a visualização da sequência das atividades é uma tarefa complexa. Goese, Bragato e Pereira (2006) afirmam que muitas empresas perdem mercado devido a não padronização de seus processos e que os integrantes de um processo devem saber os objetivos de sua implementação e para quê estão executando tais atividades, afinal um bom gerenciamento dos processos proporciona uma produção mais uniforme, aumenta a eficiência dos mesmos e reduz custos.

Ao mapear os processos empresariais na empresa, será possível a elaboração de fluxogramas, os quais permitem: "criar um entendimento comum, tornar claros os passos em um processo, identificar oportunidades de melhoria em um processo (complexidade, desperdício, atrasos, ineficiência e gargalos), revelar problemas no processo, revelar como o processo opera" (LAURINDO; ROTONDARO, 2006, p. 47).

A gestão dos processos proposta no presente trabalho tem como finalidade a otimização das atividades operacionais realizadas na empresa. Com isto, pretende-se dar maior agilidade aos processos e aumentar a eficiência da empresa, além de reduzir custos e retrabalho, instituindo, assim, a prática da melhoria contínua, revisando os processos e fazendo ajustes sempre que necessário.

Com a proposta de responder o problema e atingir os objetivos traçados, o presente trabalho está dividido em cinco capítulos. O primeiro capítulo apresentou a introdução, apresentando o tema a ser abordado no trabalho e problemática levantada; a seguir, são abordados os objetivos, geral e específicos, a justificativa da pesquisa e a estrutura do mesmo. No segundo capítulo é apresentado o método adotado para a realização do presente estudo. No terceiro capítulo caracteriza-se a empresa objeto de estudo, seu surgimento, atuação no mercado e 
funcionamento. No quarto capítulo, denominado melhorias propostas, foram apresentadas as análises e interpretações dos dados coletados durante o estudo, de forma dissertativa, visando elucidar as questões propostas pelo referente estudo. No quinto e último capítulo foram apresentadas as considerações finais e as propostas para estudos futuros.

\section{Método}

Com o propósito de atingir o objetivo proposto, o método deste estudo está estruturado da seguinte forma: caracterização da pesquisa, delineamento da pesquisa, coleta e análise dos dados e design da pesquisa. Segundo Marconi e Lakatos (2008, p. 83), o "método é o conjunto das atividades sistemáticas e racionais que, com maior segurança e economia, permite alcançar o objetivo".

A elaboração deste estudo tem por objetivo a análise e estruturação dos processos organizacionais existentes em uma empresa organizadora de eventos na cidade de Santa Maria, RS, caracterizando-se como pesquisa bibliográfica e de cunho descritivo.

A pesquisa bibliográfica foi utilizada com a finalidade de embasar os temas abordados neste estudo.

A pesquisa bibliográfica trata-se do levantamento de toda bibliografia já publicada em forma de livros, revistas, publicações avulsas em imprensa escrita, documentos eletrônicos. Sua finalidade é colocar o pesquisador em contato direto com tudo aquilo que foi escrito sobre determinado assunto, com o objetivo de permitir ao cientista o reforço paralelo na análise de suas pesquisas ou manipulação de suas informações (MARCONI; LAKATOS, 2008, p. 43).

A pesquisa de cunho descritivo, por sua vez, objetiva descrever comportamentos que podem gerar informações. Gil (2002) afirma que a pesquisa de cunho descritivo procura estabelecer relações entre as variáveis ou apresentar características de determinada população ou fenômeno, visando analisar, classificar, armazenar e interpretar esses fenômenos e variáveis, de maneira que o pesquisador não os manipule ou interceda sobre eles. 
O estudo foi desenvolvido por meio de uma pesquisa de caráter qualitativo. Conforme Hair et al. (2006, p.102), as pesquisas de caráter qualitativo "oferecem informações aprofundadas (maior compreensão) sobre algumas características" e para Collis e Hussey (2005), é mais subjetivo e envolve examinar e refletir as percepções para obter um entendimento das atividades sociais e humanas.

Quanto ao método adotado, trata-se de um estudo de caso, caracterizado por Yin (1989, p. 23) como "uma inquirição empírica que investiga um fenômeno contemporâneo dentro de um contexto da vida real, quando a fronteira entre o fenômeno e o contexto não é claramente evidente e onde múltiplas fontes de evidência são utilizadas".

A coleta dos dados foi feita por meio de observações in loco das atividades e dos processos realizados no dia-a-dia da empresa, pesquisa documental e entrevistas informais com os colaboradores da empresa. Após a coleta dos dados, foram realizadas as devidas análises e elaboração das ferramentas necessárias para a estruturação dos processos da empresa. O desenvolvimento dessas tarefas foi realizado por meio das interpretações dos autores juntamente com a gestora da empresa, utilizando a revisão de literatura elaborada como base para a fundamentação da interpretação dos dados coletados.

Por meio da análise dos dados, alcançaram-se os objetivos traçados no presente estudo e foram elaboradas ferramentas no intuito de contribuir com a empresa pesquisada.

Foram realizadas entrevistas informais com os demais trabalhadores da empresa, visando conhecer como se dá o desenvolvimento de suas atividades, assim como suas atribuições e responsabilidades dentro da empresa.

As observações in loco contribuíram para a elaboração das ferramentas propostas, juntamente com o conteúdo absorvido nas entrevistas informais, para que fossem propostas melhorias aplicáveis à rotina da empresa.

Para selecionar as ferramentas e propor a uniformização dos processos da empresa foi realizada pesquisa documental, onde foram analisados também os procedimentos e ferramentas atualmente utilizados na organização. Dessa forma, chegou-se às seguintes ações como proposta de implementação na empresa: mapear os processos organizacionais existentes 
na empresa; elaborar os fluxogramas das principais atividades; e propor a utilização de procedimentos operacionais padrão.

Em resumo, a partir da formulação do problema 'Como os processos devem ser estruturados na empresa de forma a agregar valor à mesma e a seus clientes?', foram criados o objetivo geral e os específicos, visando alcançá-lo. A partir disso, foi elaborada uma justificativa para escolha do tema a ser desenvolvido neste estudo, e então foi estruturada uma revisão de literatura aprofundando os temas que envolveriam e embasariam a prática de seu desenvolvimento. Após, foi apresentado como o método deste estudo está estruturado e como será feita a análise dos dados coletados. Por fim, são apresentadas as considerações finais a que se chegou a partir do desenvolvimento do presente estudo na empresa.

O enfoque deste trabalho foi a estruturação dos processos organizacionais da organizadora de eventos, com o intuito de agregar valor à empresa e a seus clientes. Então, na sequência é apresentada a empresa objeto de estudo, seu histórico, atuação no mercado e funcionamento.

\section{A Empresa}

A empresa objeto deste estudo é uma prestadora de serviços que organiza eventos acadêmicos, corporativos, sociais, culturais e formaturas no estado do Rio Grande do Sul e tem seu escritório estabelecido na cidade de Santa Maria (RS), além de um espaço próprio para eventos com capacidade de até 120 pessoas, situado na mesma cidade.

A empresa foi constituída em 2006 devido à oportunidade avistada na necessidade de uma empresa que se propusesse a organizar todas as etapas de eventos acadêmicos, até então realizados por professores e alunos, que muitas vezes não tinham o tempo e/ou experiências necessários para implementá-los com êxito. A partir de então foram surgindo demandas de outros tipos de eventos e a empresa foi se capacitando e entrando lentamente no ramo de eventos culturais, corporativos, sociais e formaturas. Atualmente a empresa já é referência de qualidade na organização de eventos acadêmicos, culturais, sociais, corporativos e formaturas e vem se expandindo cada vez mais. 
Em relação à sua estrutura de funcionamento, tem-se que o núcleo administrativo e financeiro gerencia tudo; o setor de design está ligado tanto a gestão da marca da empresa quanto a cada um dos eventos, enquanto que os eventos acadêmicos, sociais, culturais, corporativos e as formaturas encontram-se no nível operacionalização da empresa.

\section{Resultados}

Este capítulo objetiva apresentar a análise dos dados coletados e os resultados obtidos por meio das pesquisas documentais, observações in loco e das entrevistas informais realizadas no decorrer do estudo. A apresentação das melhorias propostas através da aplicação do método foi disposta da seguinte forma: descrição dos processos organizacionais, com a apresentação dos fluxogramas e procedimentos operacionais padrão das principais atividades da empresa.

\subsection{Processos organizacionais}

Nesta seção do trabalho são apresentadas as melhorias propostas referentes a processos organizacionais, a área em que foi realizado procurando-se agregar valor à empresa e a seus clientes. A partir das pesquisas documentais, entrevistas informais realizadas com a diretoria da empresa e da observação in loco, foi possível elencar os principais processos realizados pela empresa e estruturá-los.

\subsubsection{Procedimento operacional padrão (POP) e fluxograma}

As técnicas para estruturação dos processos organizacionais da empresa aplicadas foram o fluxograma e o procedimento operacional padrão (POP). As duas ferramentas foram escolhidas por serem uma o complemento da outra, na tentativa de atingir o objetivo da estruturação, o fluxograma representando graficamente os principais processos organizacionais implementados na empresa e o procedimento operacional padrão descrevendo detalhadamente todas as operações necessárias para a realização dos mesmos.

Foi realizado o levantamento dos processos realizados na empresa junto à diretoria e discutido quais seriam os principais, aqueles que podiam ser padronizados e exigiam maior atenção em sua execução, uma vez que podem influenciar a imagem da empresa externamente se realizados de maneira displicente e não conforme. Assim, foram elencados quatro processos 
organizacionais principais realizados, são eles: o atendimento ao público externo e aos clientes da empresa; a análise da viabilidade da organização do evento; a elaboração de orçamento; e a operacionalização de eventos.

Cabe salientar que estes são os quatro principais processos realizados pela empresa, porém, no decorrer das atividades, são observados vários outros processos secundários. Estes, não serão abordados neste trabalho, mas fica a sugestão de seu desenvolvimento em estudos futuros.

Os fluxogramas e procedimentos operacionais padrão de cada um dos quatro processos principais são apresentados a seguir.

\subsubsection{Atendimento ao público externo / clientes}

$\mathrm{O}$ atendimento ao público externo (potenciais clientes), assim como o atendimento aos clientes da empresa foi caracterizado como um dos processos principais da empresa, devido ao fato de ser a forma de relação direta da empresa com a sociedade, tendo em vista que, independente do colaborador que estiver atendendo, estará representando a empresa perante a pessoa que está sendo atendida. Se houver alguma falha na execução deste processo, a pessoa atendida não vai atribuir esta falha especificamente ao colaborador que a atendeu, vai atribuir à empresa. Então, é muito importante que a possibilidade de erro neste processo seja minimizada ao máximo. A Figura 1 - Fluxograma de Atendimento ao Público Externo / Clientes, demonstra a representação gráfica deste processo. 


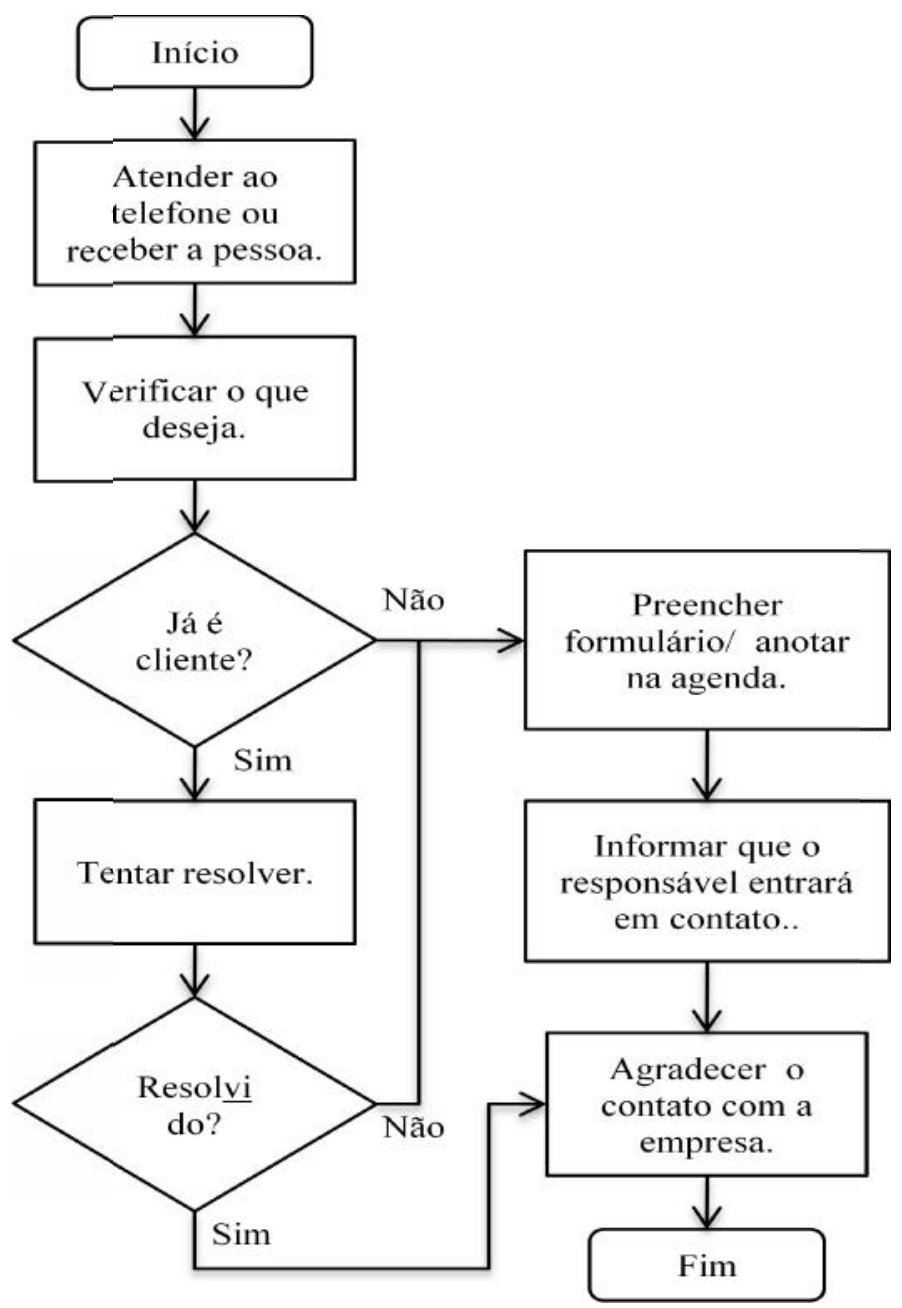

Figura 1: Fluxograma de Atendimento ao Público Externo / Clientes.

Fonte: elaborados pelos autores

A partir do fluxograma apresentado, onde são ilustradas sinteticamente cada uma das etapas pertencentes ao processo atendimento, foi elaborado o Quadro 1 - Procedimento Operacional Padrão (POP) do Atendimento. Neste quadro, as etapas que exigem maior detalhamento têm suas operações explicadas, assim como quem é responsável pela etapa, quando é necessária sua realização no processo, os itens necessários a implementação do processo, a possibilidade de falha neste processo e sua respectiva ação reparadora. Além de todos os aspectos citados, o modelo do quadro também evidencia a importância da realização de tal processo. 
Quadro 2: Procedimento Operacional Padrão (POP) do Atendimento

\begin{tabular}{|c|c|c|c|}
\hline \multicolumn{4}{|l|}{ ATENDIMENTO } \\
\hline \multicolumn{4}{|c|}{ Onde? Escritório da empresa } \\
\hline O que? & Como? & Quem? & Quando? \\
\hline $\begin{array}{l}\text { Atender ao } \\
\text { telefone ou receber } \\
\text { a pessoa. }\end{array}$ & $\begin{array}{l}\text { Atender ao telefone ou receber a pessoa } \\
\text { gentilmente no escritório e convidar para } \\
\text { sentar-se. }\end{array}$ & $\begin{array}{l}\text { Estagiária de } \\
\text { Administração } \\
\text { ou de Design }\end{array}$ & Sempre \\
\hline $\begin{array}{l}\text { Verificar o que } \\
\text { deseja. }\end{array}$ & $\begin{array}{l}\text { Verificar o que a pessoa deseja (saber mais } \\
\text { sobre a empresa, deixar currículo, pedir } \\
\text { orçamento, pegar material, pedir informação). }\end{array}$ & $\begin{array}{l}\text { Estagiária de } \\
\text { Administração } \\
\text { ou de Design }\end{array}$ & Sempre \\
\hline Já é cliente? & $\begin{array}{l}\text { Caso a pessoa já seja cliente em algum } \\
\text { serviço, verificar se pode resolver de imediato } \\
\text { sua necessidade (entrega de material, } \\
\text { informação). Se for pagamento, receber o } \\
\text { dinheiro se souber do que se trata e anotar na } \\
\text { agenda, se não, ligar para Diretora Executiva. } \\
\text { Caso não seja cliente, anotar os dados de } \\
\text { contato da pessoa (nome, telefone e e-mail), o } \\
\text { que ela deseja organizar e a data no } \\
\text { formulário de ligações ou agenda. Caso se } \\
\text { trate de formatura, preencher o formulário de } \\
\text { formaturas com a pessoa. }\end{array}$ & $\begin{array}{l}\text { Estagiária de } \\
\text { Administração } \\
\text { ou de Design }\end{array}$ & Sempre \\
\hline $\begin{array}{l}\text { Informar que o } \\
\text { responsável entrará } \\
\text { em contato. }\end{array}$ & $\begin{array}{l}\text { Informar para a pessoa que o responsável pela } \\
\text { solução de sua necessidade entrará em contato } \\
\text { com ela assim que possível. }\end{array}$ & $\begin{array}{l}\text { Estagiária de } \\
\text { Administração } \\
\text { ou de Design }\end{array}$ & Sempre \\
\hline $\begin{array}{l}\text { Agradecer o contato } \\
\text { com a empresa. }\end{array}$ & $\begin{array}{l}\text { Agradecer pela pessoa ter entrado em contato } \\
\text { com a empresa e despedir-se cordialmente. }\end{array}$ & $\begin{array}{l}\text { Estagiária de } \\
\text { Administração } \\
\text { ou de Design }\end{array}$ & Sempre \\
\hline $\begin{array}{l}\text { Itens de } \\
\text { verificação: } \\
\text { Cadeiras, mesa, } \\
\text { telefone, caneta, } \\
\text { agenda, } \\
\text { formulários. }\end{array}$ & $\begin{array}{l}\text { Verificação e ação: Pedido pela segunda vez } \\
\text { da mesma informação / Tentar resolver } \\
\text { imediatamente ligando para o responsável e } \\
\text { dando satisfação ao cliente. }\end{array}$ & $\begin{array}{l}\text { Por quê? Aten } \\
\text { forma possível } \\
\text { que entram em } \\
\text { a empresa. }\end{array}$ & $\begin{array}{l}\text { da melhor } \\
\text { pessoas } \\
\text { htato com }\end{array}$ \\
\hline
\end{tabular}

Fonte: Elaborado pelos autores.

Analisando este processo a partir do Quadro 2 - Procedimento Operacional Padrão (POP) do Atendimento, percebe-se que o mesmo está voltado a quando as estagiárias realizam o atendimento, uma vez que quando se trata das sócias-proprietárias, a realização do atendimento pode ser abreviada e unida à etapa de análise de viabilidade da organização do evento (Figura 2). 


\subsubsection{Análise de viabilidade da organização do evento}

Após o primeiro contato com a empresa, quando o cliente solicita o orçamento de algum serviço, é feita a verificação da possibilidade de a empresa poder prestar este serviço, sem prejuízo a este ou aos demais serviços já contratados. Este processo é representado abaixo, na Figura 2 - Fluxograma da Análise de Viabilidade da Organização do Evento.

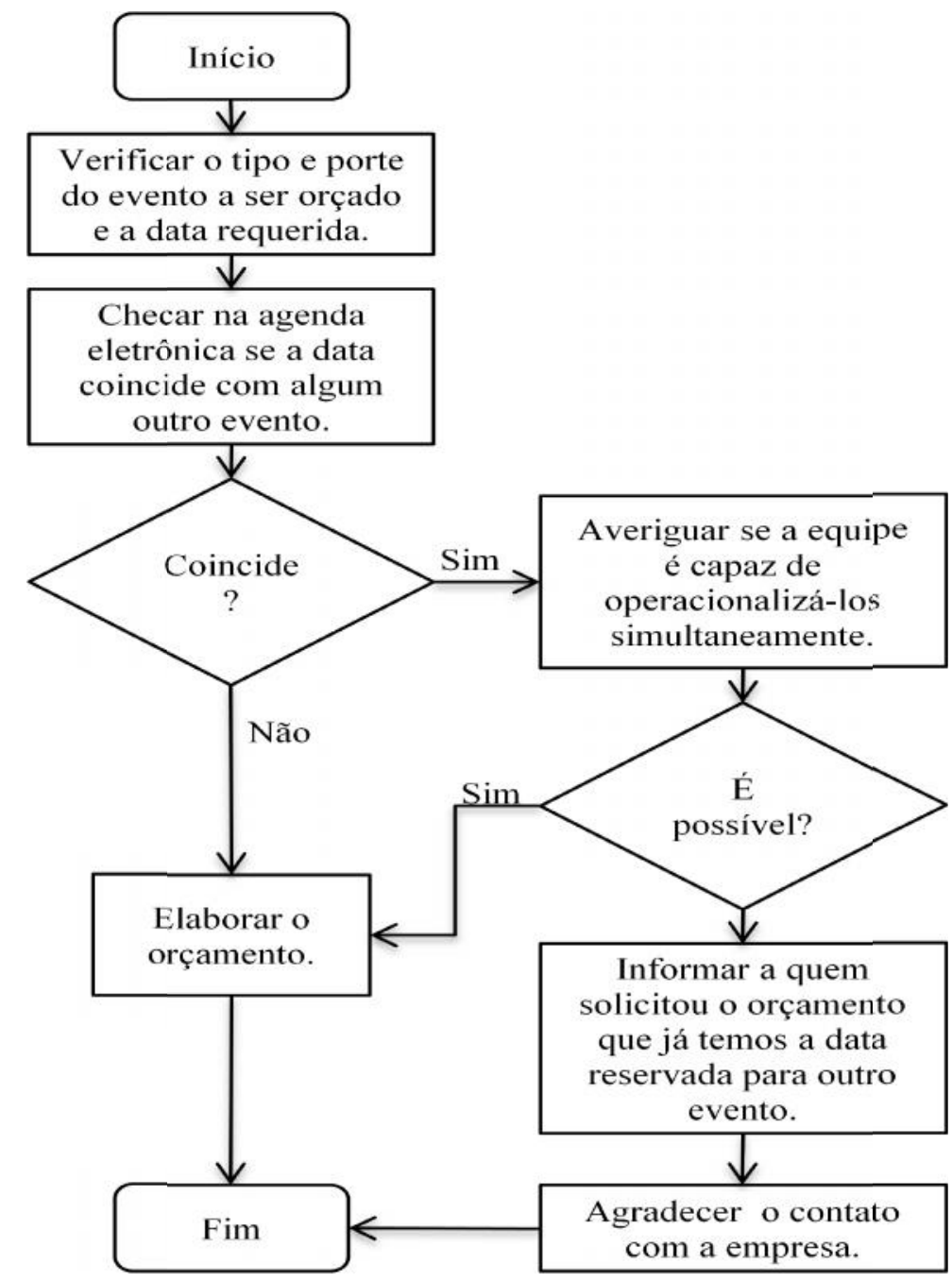

Figura 2: Fluxograma da Análise de Viabilidade da Organização do Evento

Fonte: elaborado pelos autores

Da análise do fluxograma apresentado para o processo de análise de viabilidade da organização do evento, pode-se concluir que este processo é considerado como um dos principais realizados pela empresa, devido ao fato de sua execução evitar o trabalho desnecessário de orçar uma prestação de serviço que, se aprovada pelo cliente, não poderá ser 
realizada e pela consideração em relação ao próprio cliente, informando-o que a empresa não poderá orçar para ele aquele serviço, pois já tem outros marcados para a data solicitada.

As operações realizadas nas etapas deste processo que exigem maior detalhamento são apresentadas no Quadro 3 - Procedimento Operacional Padrão (POP) da Análise de Viabilidade da Organização do Evento.

Quadro 3: Procedimento Operacional Padrão (POP) da Análise de Viabilidade da organização do Evento

\begin{tabular}{|l|l|l|l|}
\hline \multicolumn{2}{|l|}{ ANÁLISE DE VIABILIDADE DA ORGANIZAÇÃO DO EVENTO } \\
\hline Onde? Escritório da empresa & Como? & Quem? & Quando? \\
\hline O que? & $\begin{array}{l}\text { Verificar se o evento a ser orçado é } \\
\text { acadêmico, social, corporativo, } \\
\text { formatura ou cultural, o porte do } \\
\text { evento (para quantas pessoas e o que } \\
\text { requer), o local e a data a se realizar. }\end{array}$ & $\begin{array}{l}\text { Sócias- } \\
\text { proprietárias }\end{array}$ & Sempre \\
$\begin{array}{l}\text { Vevificar o tipo e porte do a ser orçado e a data } \\
\text { requerida. }\end{array}$ & $\begin{array}{l}\text { Checar na agenda se há algum serviço } \\
\text { já contratado para a data. Caso } \\
\text { afirmativo, mensurar se a equipe é } \\
\text { capaz de operacionar os dois } \\
\text { simultaneamente sem que haja algum } \\
\text { tipo de prejuízo para as partes } \\
\text { envolvidas. Se for possível, dar } \\
\text { prosseguimento à elaboração do } \\
\text { orçamento para a prestação de serviço. }\end{array}$ & $\begin{array}{l}\text { Sócias- } \\
\text { proprietárias }\end{array}$ & Sempre \\
\hline $\begin{array}{l}\text { Checar na agenda eletrônica se } \\
\text { data coincide com algum outro } \\
\text { evento. }\end{array}$ & $\begin{array}{l}\text { Entrar em contato com a pessoa que } \\
\text { solicitou o orçamento e informar a não } \\
\text { disponibilidade da data para } \\
\text { organização do evento e agradecer } \\
\text { pelo contato, pedindo para informar } \\
\text { caso haja mudança de data e ainda } \\
\text { houver interesse no nosso serviço. }\end{array}$ & $\begin{array}{l}\text { Sócias- } \\
\text { proprietárias }\end{array}$ & Sempre \\
\hline $\begin{array}{l}\text { Iterificação e ação: Após informar a } \\
\text { Computador, internet, agenda } \\
\text { eletrônica, agenda física, } \\
\text { formulários de ligações } \\
\text { preenchidos, telefone. }\end{array}$ & $\begin{array}{l}\text { indisponibilidade da data se tornar } \\
\text { viável realizar o evento/ Entrar em } \\
\text { contato com a pessoa que havia } \\
\text { solicitado orçamento e confirmar se } \\
\text { ainda há interesse em nosso serviço. } \\
\text { orçamento que já temos a data } \\
\text { reservada para outro evento. }\end{array}$ & $\begin{array}{l}\text { Por quê? Prezar pela } \\
\text { nualidade e transparestação de nossos } \\
\text { serviços. }\end{array}$ \\
\hline
\end{tabular}

Fonte: Elaborado pelos autores. 
O processo de análise de viabilidade da organização do evento é realizado essencialmente pelas sócias-proprietárias, uma vez que são elas quem tem maior domínio sobre a capacidade da empresa de atender às demandas solicitadas, podendo, assim, determinar se, independente de algum evento marcado para a data, pode-se realizar mais alguma prestação de serviço simultaneamente. Neste processo, a verificação e ação corretiva acontecem quando, por motivos não previsíveis, a empresa após informar o solicitante do orçamento da não possibilidade de prestar o serviço na data solicitada, passa a ter como viável esta possibilidade, seja porque o serviço que seria realizado foi remarcado ou pelo aumento da capacidade da empresa de atender às demandas.

Então, a empresa entra em contato novamente com o solicitante cujo orçamento foi recusado e confirma se ainda há interesse na prestação de nosso serviço. Caso afirmativo, é elaborado o orçamento e repassado ao solicitante, o próximo processo descrito.

\subsubsection{Elaboração de orçamento}

Confirmada a capacidade de realização do evento na data requerida, o próximo processo realizado pela empresa é a elaboração do orçamento solicitado. O processo de elaboração de orçamento foi eleito um dos principais processos realizados pela empresa, devido ao fato de que sua correta execução evita que a empresa desvalorize algum envolvido na prestação do serviço solicitado e, até mesmo que tenha prejuízo na execução deste serviço.

Embora a empresa possa organizar desde um evento inteiro, podendo este ser acadêmico, corporativo, cultural, social ou uma formatura, até prestar somente algum determinado serviço em um evento, como recepção, decoração, inscrições, o processo de elaboração de orçamentos pode ser considerado o mesmo para todo o tipo de orçamento requerido à empresa, pois apresenta etapas básicas a serem padronizadas em todo tipo de orçamento a ser solicitado. A Figura 3 - Fluxograma da Elaboração de Orçamento, a seguir, representa graficamente o processo de elaboração de orçamento, apresentando as etapas básicas inerentes a este processo. 


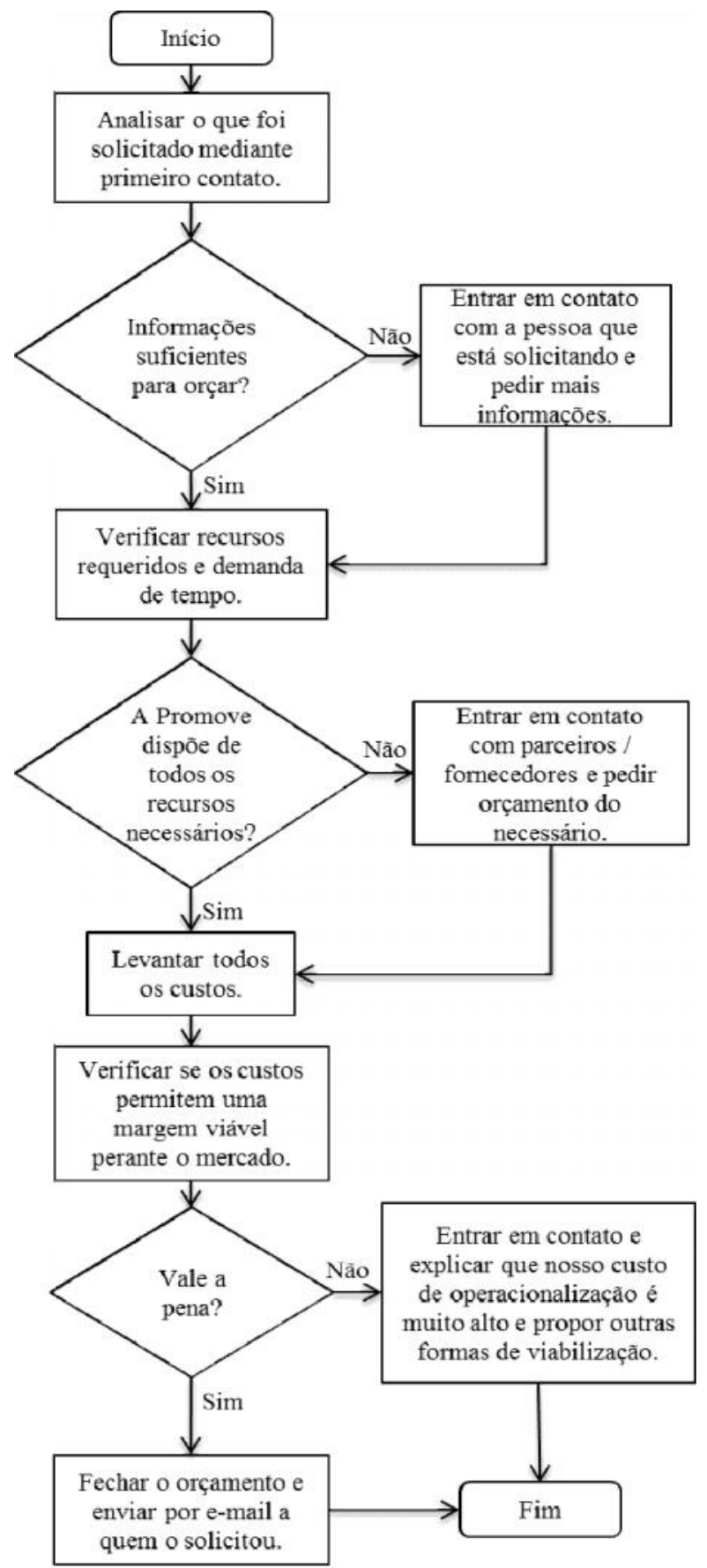

Figura 3: Fluxograma da Elaboração de Orçamento

Fonte: elaborado pelos autores

A partir da Figura 3 - Fluxograma da Elaboração de Orçamento, foi elaborado o Quadro 4 Procedimento Operacional Padrão (POP) da Elaboração de Orçamento, visando elucidar as etapas que necessitavam maiores informações e os respectivos responsáveis por cada uma. 
Quadro 4: Procedimento Operacional Padrão (POP) da Elaboração de Orçamento.

\begin{tabular}{|c|c|c|c|}
\hline \multicolumn{4}{|c|}{ ELABORAÇÃO DE ORÇAMENTO } \\
\hline \multicolumn{4}{|c|}{ Onde? Escritório da empresa } \\
\hline O que? & Como? & Quem? & Quando? \\
\hline $\begin{array}{l}\text { Analisar o que foi } \\
\text { solicitado mediante } \\
\text { primeiro contato. }\end{array}$ & $\begin{array}{l}\text { Analisar se as informações repassadas no } \\
\text { primeiro contato com a empresa ao pedir o } \\
\text { orçamento são suficientes para sua } \\
\text { elaboração. }\end{array}$ & $\begin{array}{l}\text { Sócias- } \\
\text { proprietárias }\end{array}$ & Sempre \\
\hline $\begin{array}{l}\text { Entrar em contato com } \\
\text { a pessoa que está } \\
\text { solicitando e pedir } \\
\text { mais informações. }\end{array}$ & $\begin{array}{l}\text { Caso as informações não sejam suficientes, } \\
\text { entrar em contato com a pessoa e pedir } \\
\text { mais detalhes, se possível, marcar uma } \\
\text { reunião. }\end{array}$ & $\begin{array}{l}\text { Sócias- } \\
\text { proprietárias } \\
\text { e Estagiária de } \\
\text { Administração }\end{array}$ & Sempre \\
\hline $\begin{array}{l}\text { Verificar recursos } \\
\text { requeridos e demanda } \\
\text { de tempo. }\end{array}$ & $\begin{array}{l}\text { Caso as informações sejam suficientes, } \\
\text { verificar tudo o que vai ser necessário para } \\
\text { a prestação de serviço: materiais, pessoal, } \\
\text { demanda de tempo. }\end{array}$ & $\begin{array}{l}\text { Sócias- } \\
\text { proprietárias }\end{array}$ & Sempre \\
\hline $\begin{array}{l}\text { A empresa dispõe de } \\
\text { todos os recursos } \\
\text { necessários? }\end{array}$ & $\begin{array}{l}\text { Se a empresa não dispõe de algum recurso } \\
\text { que será necessário para a execução do } \\
\text { evento, entrar em contato com as empresas } \\
\text { parceiras que podem realizar esta parte e } \\
\text { fornecedores para solicitar orçamento da } \\
\text { terceirização do serviço. }\end{array}$ & $\begin{array}{l}\text { Sócias- } \\
\text { proprietárias } \\
\text { e Estagiária de } \\
\text { Administração }\end{array}$ & Sempre \\
\hline $\begin{array}{l}\text { Levantar todos os } \\
\text { custos. }\end{array}$ & $\begin{array}{l}\text { Levantar todos os custos inerentes ao } \\
\text { serviço a ser prestado, juntar todos em uma } \\
\text { planilha e analisar se o custo total permite } \\
\text { uma margem de lucro viável perante os } \\
\text { preços aplicados no mercado para a } \\
\text { prestação do mesmo tipo de serviço. }\end{array}$ & $\begin{array}{l}\text { Sócias- } \\
\text { proprietárias } \\
\text { e Estagiária de } \\
\text { Administração }\end{array}$ & Sempre \\
\hline $\begin{array}{l}\text { Entrar em contato e } \\
\text { explicar que nosso } \\
\text { custo de } \\
\text { operacionalização é } \\
\text { muito alto e propor } \\
\text { outras formas de } \\
\text { viabilização }\end{array}$ & $\begin{array}{l}\text { Se a prestação do serviço vale a pena, } \\
\text { fecha-se o orçamento e ele é enviado via e- } \\
\text { mail para o solicitante. Caso o custo de } \\
\text { operacionalização fique muito acima do } \\
\text { aplicado no mercado, verificar os itens que } \\
\text { o encarecem e entrar em contato com a } \\
\text { solicitante passando o valor e explicando } \\
\text { que nosso custo é muito alto, devido a tais } \\
\text { itens e propor alternativas a este item na } \\
\text { execução do evento. }\end{array}$ & $\begin{array}{l}\text { Sócias- } \\
\text { proprietárias }\end{array}$ & Sempre \\
\hline $\begin{array}{l}\text { Itens de } \\
\text { verificação: } \\
\text { Cadeiras, mesa, } \\
\text { telefone, caneta, }\end{array}$ & $\begin{array}{l}\text { Verificação e ação: Não houver nenhum } \\
\text { retorno por parte do solicitante/ Entrar em } \\
\text { contato para verificar o correto } \\
\text { recebimento do orçamento e situação. }\end{array}$ & $\begin{array}{l}\text { Por quê? Realiz } \\
\text { trabalho de qual } \\
\text { desvalorizar ner } \\
\text { envolvido nesta }\end{array}$ & $\begin{array}{l}\text { um } \\
\text { de sem } \\
\text { m estação de }\end{array}$ \\
\hline
\end{tabular}




\begin{tabular}{|l|l|l|}
\hline $\begin{array}{l}\text { agenda, } \\
\text { formulários, } \\
\text { software excel, } \\
\text { internet, e-mail. }\end{array}$ & & serviço. \\
\hline
\end{tabular}

Fonte: Elaborado pelos autores.

Pode-se visualizar que na elaboração dos orçamentos, não é apenas um nível hierárquico que se envolve - além das sócias-proprietárias, a estagiária de administração também auxilia na elaboração deste processo - algumas vezes nas etapas de contato com o solicitante do orçamento, fornecedores e levantamento de todos os custos inerentes à prestação do serviço.

Vale ressaltar que na elaboração do orçamento, é realizada também uma análise se a empresa conseguirá orçar esta prestação de serviço conforme o mercado e, em caso negativo, a empresa informa isto ao cliente, assim como as razões que deixam a operacionalização tão alta, evitando, dessa forma, que o cliente possa se sentir enganado posteriormente.

Se, após este processo concluído, com o envio do orçamento ao solicitante, não houver nenhum retorno do mesmo à empresa, é entrado em contato com o mesmo para verificar as seguintes possibilidades: se ele recebeu o orçamento e a situação; se ele ainda está avaliando o orçamento ou mesmo a viabilidade da concretização do evento; ou, ainda, na pior das hipóteses, se já fechou com outra empresa. Essa ligação para obter o feedback do cliente é de suma importância para a empresa, pois serve para que a mesma possa se organizar diante das colocações do cliente, sejam elas positivas ou negativas. Caso o cliente tenha fechado com alguma outra empresa, é importante saber se foi por questões de preço, se foi pelo atendimento prestado, por incapacidade da empresa de atendê-lo na data requerida, ou qualquer outro motivo.

De qualquer forma, a empresa deverá valer-se desse feedback do cliente para se ajustar cada vez mais ao mercado, seja em valores, serviços ou adequação da estrutura da empresa em mão de obra qualificada, número adequado de pessoas para trabalhar, disponibilidade de mais e melhores locais para eventos, etc., seguindo os apelos de uma demanda cada vez mais exigente. Conforme Cannie (1995), o feedback do cliente que a empresa perdeu é muito importante, afinal os clientes sabem o que deve ser melhorado a fim de atender às suas expectativas. $O$ autor salienta que clientes que foram perdidos para a concorrência 
representam um sistema de advertência prévio, uma vez que o estímulo que motivou a perda de um cliente pode estar incomodando outras pessoas também. Logo, a obtenção deste feedback, pode e deve ser usada para melhorar os processos da empresa e evitar problemas futuros.

Quando aprovados e confirmados todos os itens do orçamento, segue-se ao planejamento e organização do evento ou serviço em questão. O processo de operacionalização de eventos é apresentado na sequência. Já o processo de operacionalização de um serviço específico não foi considerado como processo principal para o estudo, devido a cada tipo de serviço requisitado ter suas peculiaridades.

\subsubsection{Operacionalização de eventos}

Quando a empresa objeto do estudo é contratada para a organização de um evento, após aprovado e confirmado o orçamento, é fechado o contrato com o cliente em questão e a seguir inicia-se a fase de planejamento do evento para a posterior operacionalização do mesmo.

Durante a fase de planejamento, primeiramente é feita a designação da equipe para a organização do evento, conforme os itens requisitados mediante contrato. Então, as tarefas são divididas entre os membros da equipe, que no decorrer do desenvolvimento das atividades vão se comunicando e acompanhando o desenvolver das atividades dos demais. Quando necessário, como quando há sobrecarga não esperada de algum membro ou dificuldade de alguém na realização de alguma tarefa, é feita uma redistribuição de atividades ou mesmo oferecido o apoio de mais algum membro para o desenvolvimento da atividade.

Conforme os itens vão sendo finalizados, são apresentados aos clientes para sua apreciação e aprovação, para então passar às etapas seguintes necessárias à organização do evento. Tendo todos os itens das fases de preparação do evento concluídos, parte-se para a fase de planejamento do dia do evento, muito bem ilustrado no fluxograma apresentado na Figura 4.

Todos os eventos organizados pela empresa em questão compartilham de uma estrutura geral básica em sua implementação. Por isso, apesar de cada tipo de evento ter suas peculiaridades, ao se organizar um evento acadêmico, social, corporativo, cultural ou formatura, alguns itens sempre são executados. Baseando-se nisso, foram estruturados o fluxograma e o 
procedimento operacional padrão da operacionalização de eventos, apresentados respectivamente na Figura 4 - Fluxograma da Operacionalização de Eventos e no Quadro 5 Procedimento Operacional Padrão (POP) da Operacionalização de Eventos. 


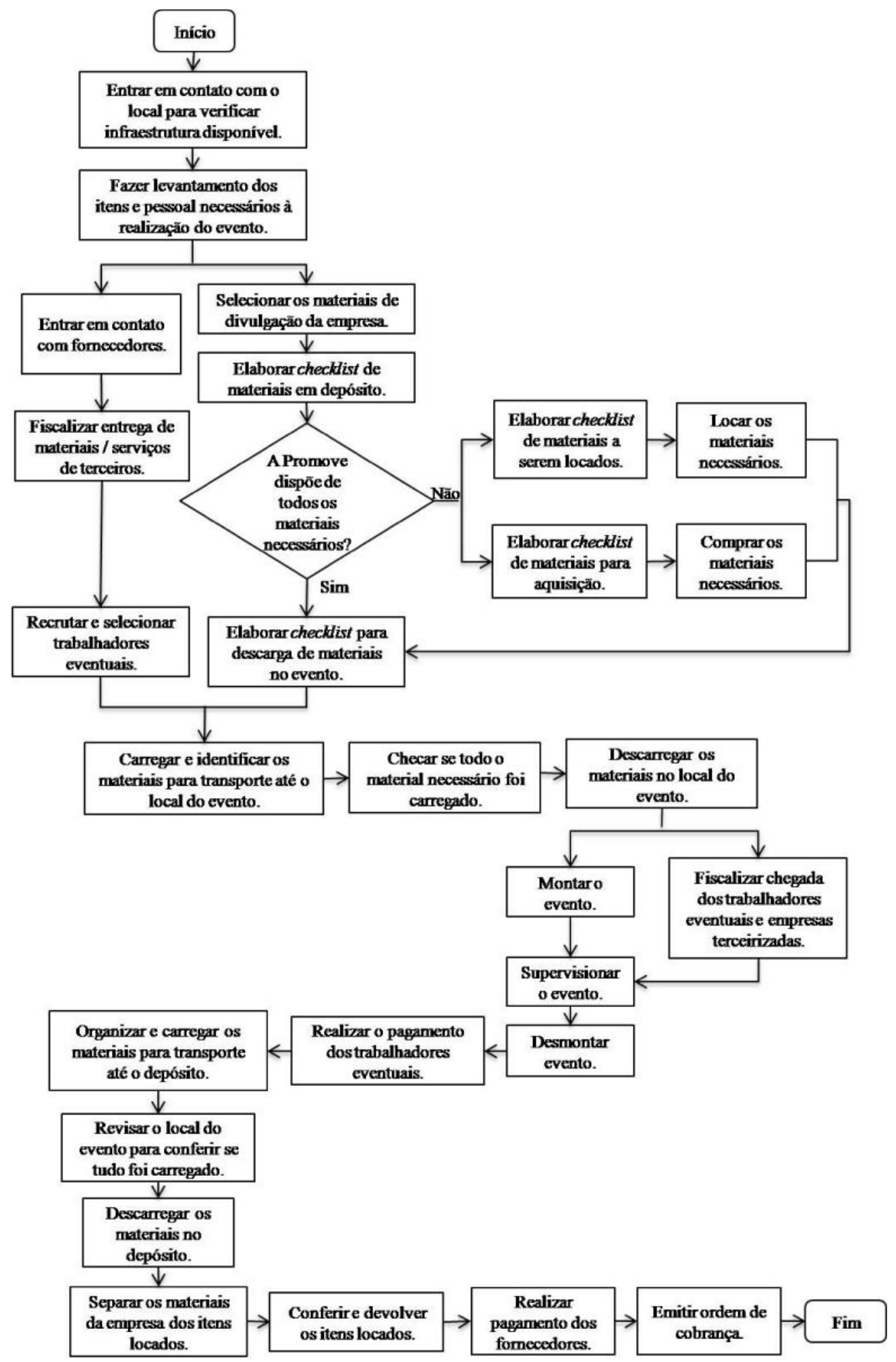

Figura 4: Fluxograma da Operacionalização de Eventos

Fonte: Elaborado pelos autores. 
Na Figura 4 - Fluxograma da Operacionalização de Eventos são apresentadas as etapas gerais da operacionalização de eventos organizados pela empresa, sem entrar em detalhes que podem variar conforme o tipo de evento que está sendo organizado e o Quadro 5 Procedimento Operacional Padrão (POP) da Operacionalização de Eventos, apresenta as etapas que exigem explicações são detalhadas para maior compreensão do processo.

Quadro 5: Procedimento Operacional Padrão (POP) da Operacionalização de Eventos

\begin{tabular}{|c|c|c|c|}
\hline \multicolumn{4}{|c|}{ OPERACIONALIZAÇÃO DE EVENTOS } \\
\hline \multicolumn{4}{|c|}{ Onde? Escritório da empresa e Local do Evento } \\
\hline O que? & Como? & Quem? & Quando? \\
\hline $\begin{array}{l}\text { Entrar em contato } \\
\text { com o local para } \\
\text { verificar } \\
\text { infraestrutura } \\
\text { disponível. }\end{array}$ & $\begin{array}{l}\text { Entrar em contato com o local onde o } \\
\text { evento será realizado para verificar a } \\
\text { infraestrutura que o local dispõe, medidas } \\
\text { da área, horários para carga e descarga de } \\
\text { materiais e montagem e desmontagem do } \\
\text { evento. }\end{array}$ & $\begin{array}{l}\text { Sócias- } \\
\text { proprietárias }\end{array}$ & Sempre \\
\hline $\begin{array}{l}\text { Fazer levantamento de } \\
\text { itens e pessoal } \\
\text { necessários à realização } \\
\text { do evento. }\end{array}$ & $\begin{array}{l}\text { Realizar o levantamento do que será } \\
\text { necessário para o evento (material, pessoal, } \\
\text { serviços), tendo em vista o que o local } \\
\text { fornece e suas regras. }\end{array}$ & $\begin{array}{l}\text { Sócias- } \\
\text { proprietárias }\end{array}$ & Sempre \\
\hline $\begin{array}{l}\text { Selecionar os materiais } \\
\text { de divulgação da } \\
\text { empresa. }\end{array}$ & $\begin{array}{l}\text { Selecionar os materiais e meios de } \\
\text { divulgação da empresa que serão utilizados } \\
\text { durante o evento, se necessário criar } \\
\text { materiais específicos para aquele evento. }\end{array}$ & $\begin{array}{l}\text { Sócias- } \\
\text { proprietárias e } \\
\text { Estagiária de } \\
\text { Design }\end{array}$ & Sempre \\
\hline Elaborar checklists. & $\begin{array}{l}\text { Tendo em vista o que será necessário para } \\
\text { a organização do evento, é elaborado } \\
\text { checklist com base nos materiais que se } \\
\text { tem em depósito. A partir disso, para os } \\
\text { itens que a empresa não dispõe são } \\
\text { elaborados checklists para os materiais que } \\
\text { podem ser locados e para os que podem ser } \\
\text { comprados. Após todos os materiais em } \\
\text { mãos, é elaborado um checklist para } \\
\text { descarga dos materiais no local do evento, } \\
\text { uma vez que uma parte do material pode } \\
\text { ter que ir para a sala reserva, outra parte } \\
\text { para o salão principal, para a cozinha, etc. }\end{array}$ & $\begin{array}{l}\text { Sócias- } \\
\text { proprietárias e } \\
\text { Supervisor } \\
\text { Logístico }\end{array}$ & Sempre \\
\hline
\end{tabular}




\begin{tabular}{|c|c|c|c|}
\hline $\begin{array}{l}\text { Recrutar e selecionar } \\
\text { trabalhadores eventuais. }\end{array}$ & $\begin{array}{l}\text { De acordo com o porte do evento há uma } \\
\text { demanda de pessoal para trabalhar naquele } \\
\text { evento específico. São alguns trabalhadores } \\
\text { eventuais os garçons, auxiliares de cozinha, } \\
\text { recepcionistas, ajudantes de palco, pessoal } \\
\text { para trabalhar no credenciamento, } \\
\text { recreacionistas, etc. Estes trabalhadores são } \\
\text { selecionados através de análise de currículo, } \\
\text { entrevista quando possível e conforme } \\
\text { experiências de trabalhos anteriores. }\end{array}$ & $\begin{array}{l}\text { Sócias- } \\
\text { proprietárias e } \\
\text { Estagiária de } \\
\text { Administração }\end{array}$ & Sempre \\
\hline $\begin{array}{l}\text { Descarregar os } \\
\text { materiais no local do } \\
\text { evento. }\end{array}$ & $\begin{array}{l}\text { Esta etapa é feita com base no checklist } \\
\text { para descarga de materiais no local do } \\
\text { evento, para que os materiais já sejam } \\
\text { descarregados no local onde serão } \\
\text { utilizados na montagem do evento. }\end{array}$ & $\begin{array}{l}\text { Supervisor } \\
\text { Logístico }\end{array}$ & Sempre \\
\hline $\begin{array}{l}\text { Realizar o pagamento } \\
\text { dos trabalhadores } \\
\text { eventuais. }\end{array}$ & $\begin{array}{l}\text { Após o evento é realizado o pagamento dos } \\
\text { trabalhadores eventuais conforme acertado } \\
\text { na contratação e é pedido um recibo } \\
\text { comprovando o pagamento da prestação do } \\
\text { serviço. }\end{array}$ & $\begin{array}{l}\text { Sócias- } \\
\text { proprietárias }\end{array}$ & Sempre \\
\hline $\begin{array}{l}\text { Descarregar os } \\
\text { materiais no depósito. }\end{array}$ & $\begin{array}{l}\text { Os materiais que retornam do evento } \\
\text { devem ser organizados, limpos e guardados } \\
\text { em seus devidos locais no depósito da } \\
\text { empresa, separando-se os itens locados } \\
\text { para sua devolução. }\end{array}$ & $\begin{array}{l}\text { Supervisor } \\
\text { Logístico }\end{array}$ & Sempre \\
\hline $\begin{array}{l}\text { Realizar pagamento dos } \\
\text { fornecedores. }\end{array}$ & $\begin{array}{l}\text { Após o término do evento, são realizados o } \\
\text { pagamento total dos fornecedores ou saldo } \\
\text { restante, conforme acordo inicial. }\end{array}$ & $\begin{array}{l}\text { Sócias- } \\
\text { proprietárias e } \\
\text { Supervisor } \\
\text { Logístico }\end{array}$ & Sempre \\
\hline $\begin{array}{l}\text { Emitir ordem de } \\
\text { cobrança. }\end{array}$ & $\begin{array}{l}\text { Por fim, é emitida a ordem de cobrança ao } \\
\text { cliente para o pagamento, total ou do saldo } \\
\text { restante conforme acordado, referente à } \\
\text { organização do evento. }\end{array}$ & $\begin{array}{l}\text { Sócias- } \\
\text { proprietárias }\end{array}$ & Sempre \\
\hline $\begin{array}{l}\text { Itens de verificação: } \\
\text { Telefone, e-mail, } \\
\text { internet, Excel, } \\
\text { contrato, automóveis, } \\
\text { dinheiro, materiais } \\
\text { necessários no dia do } \\
\text { evento. }\end{array}$ & $\begin{array}{l}\text { Verificação e ação: Imprevistos durante o } \\
\text { evento. / Ter sempre durante o evento } \\
\text { contato de fornecedores e trabalhadores } \\
\text { eventuais que possam substituir ou } \\
\text { assessorar os já acordados caso seja } \\
\text { necessário. }\end{array}$ & $\begin{array}{l}\text { Por quê? Para } \\
\text { proporcionar } \\
\text { um evento } \\
\text { bem sucedido } \\
\text { e que encante } \\
\text { a todos os } \\
\text { presentes. }\end{array}$ & \\
\hline
\end{tabular}

Fonte: Elaborado pelos autores. 
Na elaboração do Quadro 5 - Procedimento Operacional Padrão (POP) da Operacionalização de Eventos, salienta-se que etapas mais específicas deste processo, como montagem e supervisão do evento não são explicadas detalhadamente porque variam conforme o tipo de evento que está sendo realizado. Sem dúvida, o processo maior da empresa, a operacionalização dos eventos conta com muitas etapas, cada uma com sua importância, exigindo muita atenção durante sua execução. A não operacionalização de uma das etapas pode colocar em risco toda a organização do evento, e neste sentido, é muito importante que estejam claras as etapas a serem realizadas e a representação gráfica deste processo contribui muito para isso.

A partir das melhorias propostas para o melhor funcionamento da empresa, a seguir são apresentadas as principais contribuições que trouxe o desenvolvimento deste estudo.

\section{Considerações Finais}

Empresas prestadoras de serviços, para obterem vantagem competitiva perante os concorrentes e destacarem-se no mercado como referência, devem prezar por um padrão de decisões coerente, tendo seu processo de fornecimento projetado conforme a qualidade esperada pelos clientes. Muitas empresas no ramo de serviços perdem uma parcela do mercado devido a não padronização de seus processos, pois nestas empresas, a visualização da sequência das atividades é uma tarefa difícil, todavia, muito importante.

A realização deste estudo justificou-se, sobretudo, pela necessidade de maior agilidade junto aos processos organizacionais da empresa, aumentando sua eficiência, além de reduzir custos e retrabalhos, instituindo, assim, a prática da melhoria contínua, através do hábito criado na empresa de se revisar os processos e fazer os devidos ajustes, sempre que necessário.

Para atingir os objetivos do estudo, foram efetuadas observações in loco do cotidiano da empresa e, especificamente, das atividades desenvolvidas na organização, averiguando as falhas presentes na execução de processos ainda não padronizados. Foram realizadas entrevistas informais com a diretoria, identificando os valores e princípios seguidos pela organização. Da mesma forma, foram analisados documentos da instituição para identificar as 
ferramentas que a empresa utilizava para uniformização de etapas de seus processos, para ajudar na estruturação dos principais processos da empresa.

No decorrer do estudo, percebeu-se que a estruturação dos processos da empresa poderia servir como uma excelente ferramenta, oportunizando, por meio da uniformização dos processos, a eliminação das etapas desnecessárias e o aprimoramento do fluxo de trabalho. Essa padronização propiciou aos colaboradores e clientes a visualização ampla e clara das atividades da empresa, fornecendo maior eficiência, agilidade e confiabilidade nos serviços prestados, bem como a otimização de pessoas, equipamentos e materiais na implementação dos serviços prestados pela organizadora de eventos.

Por meio da análise dos processos organizacionais existentes na empresa, a fim de aumentar a eficiência na realização de suas atividades, resolveu-se estruturar seus processos principais. A partir das entrevistas informais, observações in loco e pesquisas documentais chegou-se a quatro processos principais: o atendimento ao público externo e aos clientes da empresa, a análise da viabilidade da organização do evento, a elaboração de orçamento e a operacionalização de eventos.

Com a finalidade de buscar ferramentas que dessem suporte para os colaboradores na compreensão e visualização da uniformização das atividades, foram criados os fluxogramas e procedimentos operacionais padrão dos principais processos organizacionais realizados na empresa. Esses procedimentos listam as etapas a serem desenvolvidas, explicam as tarefas pertencentes à cada etapa, o local onde o processo é realizado, a pessoa responsável por cada etapa, a periodicidade da realização da mesma, as possíveis falhas que podem ocorrer, mesmo quando da correta implementação do processo, bem como as condições necessárias para o processo ser concretizado.

Com a implantação das práticas de uniformização dos processos propostas no presente estudo, a empresa é capaz de promover o estabelecimento de padrões de rotinas diárias e elaborar estratégias para guiar a organização no alcance de seus objetivos.

Em relação às limitações do estudo, pode-se mencionar o pouco tempo para a constatação dos resultados e a implementação dos ajustes necessários, além do fato de que, por se tratar de um estudo de caso, os resultados talvez não possam ser generalizados a outras organizações. 
Como sugestão para estudos futuros, propõe-se à academia mais estudos sobre a área de eventos na forma de prestação de serviços e à empresa objeto do estudo, a continuação do estudo dos processos organizacionais, principalmente os relacionados aos fornecedores, assim como a elaboração de um planejamento estratégico, realizado de forma informal até o momento, todavia imprescindível para a ampliação da atuação da empresa no mercado.

Conclui-se, portanto, que o desenvolvimento deste estudo propiciou melhorias para a empresa ao atingir o seu objetivo geral, ou seja, a estruturação dos processos organizacionais existentes na empresa, agregando valor tanto à empresa quanto a seus clientes através da uniformização dos mesmos; e possibilitou a aplicação prática da teoria estudada durante o período da graduação, contribuindo para uma formação profissional enriquecida por meio da união do conhecimento à prática.

\section{Referências}

CANNIE, J. K. Como Recuperar Clientes Perdidos (Eles Valem Ouro!). São Paulo: Nobel, 1995.

CESCA, C. G. G. Organização de eventos: manual para planejamento e execução. 9. ed. São Paulo: Summus, 2008.

COLLIS, J.; HUSSEY, R. Pesquisa em administração: um guia prático para alunos de graduação e pós-graduação. 2 ed. Porto Alegre: Bookman, 2005.

CORRÊA, H. L.; GIANESI, I. G. N. Gestão estratégica de operações de serviço. In: XXX ASSEMBLÉIA DO CONSELHO LATINO-AMERICANO DE ESCOLASS DE ADMINISTRAÇÃO. 1995. São Paulo. Anais. São Paulo: CLADEA, 1995. Disponível em:<http://www.correa.com.br/biblioteca/artigos/A03_Cladea_1995_Gestao_estrategica_de_operacoe s.pdf>. Acesso em: 30 jun. 2011.

GIL, A. C. Como elaborar projetos de pesquisa. 4. ed. São Paulo: Atlas, 2002.

GOESE, I. B.; BRAGATO, L. L. V.; PEREIRA, N. N. A padronização dos processos: uma ferramenta gerencial. Revista Universo Acadêmico, 9. ed. Espírito Santo, jan./jun. 2006.

GONÇALVES, E. L. Processo, que processo? Revista de Administração de Empresas, São Paulo, v. 40, n.4, p. 8-19, out./dez. 2000.

HAIR, J. F.; BABIN, B.; MONEY, A. H.; SOMOUEL, P. Fundamentos de métodos de pesquisa em administração. 1. ed. São Paulo: Bookman, 2006.

LAURINDO, F. J. B.; ROTONDARO, R. G. Gestão integrada de processos e da tecnologia da informação. São Paulo: Atlas, 2006.

MARCONI, M. A.; LAKATOS; E. M. Metodologia científica. 5. ed. São Paulo: Atlas, 2008.

MARTIN, V. Manual prático de eventos. 1. ed. São Paulo: Atlas, 2007. 
MATIAS, M. Organização de eventos: procedimentos e técnicas. 4. ed. Barueri, São Paulo: Manole, 2007. . Organização de Eventos: procedimentos e técnicas. São Paulo: Manole, 2001.

SANTOS, L. C. Projeto e análise de processos de serviços: avaliação de técnicas e aplicação em uma biblioteca. 2000. Dissertação (Dissertação para obtenção do título de mestre em Engenharia de Produção) - Universidade Federal de Santa Catarina, Florianópolis, 2000.

SENTANIN, O. F. Gestão por processos em uma empresa de P\&D. In: ENCONTRO NACIONAL DE ENGENHARIA DE PRODUÇÃO. 2003. Minas Gerais. Anais. Minas Gerais: ENEGEP, 2003. Disponível em: <http://www.abepro.org.br/biblioteca/ENEGEP2003_TR0702_1473.pdf>. Acesso em: 06 jul. 2011.

VELOSO, D. Organização de eventos e solenidades. Goiânia: AB, 2001.

YIN, R. K. Case Study Research: Design and Methods. USA: Sage Publications Inc., 1989.

Recebido em: 15/06/2012 ( $1^{\text {a }}$ versão) $25 / 10 / 2012$ ( $2^{\mathrm{a}}$ versão)

Aprovado em: 29/10/2012 